\title{
HOMENAJE AL DR. JOSÉ BERENGUER RODRÍGUEZ ${ }^{1}$
}

\author{
TRIBUTE TO DR. JOSÉ BERENGUER RODRÍGUEZ
}

\author{
Carlos González Godoy²
}

\begin{abstract}
Referirme en esta solemne ocasión al arqueólogo José Berenguer Rodríguez -"Pepe" Berenguer como lo conocemos, si me disculpa la naturalidad-, es para mí un doble honor. Por un lado, poder organizar una síntesis sobre la prolífica y trascendente obra de uno de los arqueólogos más importantes de Chile.Y por otro, tener la oportunidad de rendir, a nombre del Comité Organizador del Taller Internacional Qhapaq Ñan II en la ciudad de Salta, Argentina, un justo y sentido homenaje al colega, doctor, profesor, maestro y amigo, por sus significativos aportes a nuestra disciplina, a la arqueología de la vialidad prehispánica y, en particular, del Inka.

Para quienes tenemos la fortuna de conocerlo más personalmente, Berenguer es un maestro con el ejemplo, no con los aspavientos del que demanda pleitesía y un vano y ciego seguimiento personal, sino con el trabajo detallado, con la conversación y el diálogo mayéutico que introduce interrogantes y desafía el quehacer propio, escuchando distintas opiniones que generan una fructífera discusión. De la misma manera, lo es en la sobria erudición y en propiciar, generosamente, variadas oportunidades a quienes pretendemos seguir sus huellas. Maestro en la sencillez profunda y humana, que seguro -ahora mismo-cree no merecer este justo reconocimiento.

Se puede decir que Berenguer es el primer arqueólogo profesional chileno formado en una institución universitaria, por aquel entonces en una naciente carrera de arqueología, ya que Luis Rodríguez, quien se tituló antes de la Licenciatura en Prehistoria y Arqueología de la Universidad de Chile, no se dedicó a la profesión. Berenguer logró su título de arqueólogo en 1975 con la tesis: "Aspectos diferenciales de la influencia Tiwanaku en Chile"; una temática que se convirtió en una línea de investigación preeminente durante su carrera, pasando a ser uno de los principales especialistas sobre Tiwanaku (Berenguer 2000). En 2002
\end{abstract}

obtiene el grado de Doctor en Antropología (PhD) por la University of Illinois, Urbana-Champaign, con la tesis: "Tráfico de caravanas, interacción interregional y cambio cultural en la prehistoria tardía del desierto de Atacama"; publicada en 2004 como libro por la Editorial Sirawi. En ese trabajo discute, entre varios temas, los modelos caravaneros -particularmente el de Movilidad Giratoria-, las interacciones interregionales y la arqueología vial, marcando un hito en estas materias. Por lo mismo, Nielsen (2006) señalaba: "es que en los próximos años no podremos discutir la interacción interregional en los Andes circumpuneños sin "dialogar" con esta obra" (Nielsen 2006:161).

En el ámbito de la docencia universitaria, desde 1978 a 1982, y luego entre 1992 y 1999, impartió clases en la carrera de Arqueología del Departamento de Antropología de la Universidad de Chile. En las aulas fue un profesor acucioso con la rigurosidad de las lecturas, en la discusión fecunda y en las explicaciones e interpretaciones fundamentadas. Puedo dar fe, como su alumno, que como profesor era implacable en exigir datos para respaldar inferencias. Paralelamente, los trabajos de campo de sus proyectos se han convertido en verdaderas escuelas donde se han formado alumnas y alumnos. En forma intermedia, trabajó en 1979 como investigador del Instituto Otavaleño de Antropología en Ecuador (Sinclaire 2018) ${ }^{1}$.

En el ámbito investigativo, por más de 45 años ha desentrañado el pasado del Valle del Alto Loa y Santa Bárbara, convirtiéndolo en uno de los espacios con mayor información arqueológica en Chile, que se suma a los trabajos sistemáticos emprendidos por otros equipos en los valles de Azapa y Camarones, así como también en el Loa Superior en su conjunto. En esta última región, correspondiente a la cuenca superior del Río Loa y sus tributarios (Aldunate et al. 1986), nuestro homenajeado

\footnotetext{
${ }^{1}$ Leído en el marco del Taller Internacional Qhapaq Nan II, Salta, Argentina, 26 de octubre de 2017.

${ }^{2}$ Instituto de Investigación en Ciencias Sociales y Educación, Universidad de Atacama, Copiapó, Chile. carlos.gonzalezg@uda.cl, Coordinador General, Taller Internacional Qhapaq Ñan II.
} 
fue uno de los fundadores y participó en el recordado "Grupo Toconce", que desde 1977, junto con Victoria Castro, Carlos Aldunate y otros, sentó un precedente teórico y metodológico sobre como desarrollar una investigación arqueológica con las comunidades indígenas y con los aportes de la etnografía andina, siendo hasta el día de hoy un referente no solo en el Norte Grande, sino en todo Chile.

Desde 1976 hasta el presente, ha llevado a cabo proyectos de investigación que han escudriñado en diversos aspectos de la arqueología y prehistoria del norte de Chile, como igualmente en las interrelaciones con espacios culturales puneños y transpuneños. Desde 1984 sus investigaciones han contado con el apoyo de WennerGren Foundation, Tinker Foundation, Fondo Nacional de Desarrollo Científico y Tecnológico (FONDECYT, Chile) y Fondo Nacional para el Desarrollo Cultural y las Artes (FONDART, Chile), entre otros.

En su trabajo ha buscado siempre comprender procesos culturales y la centralidad de conceptos como lugar, paisaje, ambiente y territorio en el desarrollo de las sociedades. En consecuencia, para él hablar de paisajes culturales es una redundancia, ya que "lo social" y "lo espacial" son, en sus propias palabras, "dos caras de una misma moneda" (Berenguer 2004a:20). Este planteamiento es fruto de su interés sostenido por integrar los aportes empíricos y teóricos de la geografía -la ciencia del espacio- en sus investigaciones arqueológicas; carrera que también cursó entre 1971 y 1973 en la Universidad de Chile, pero que no concluyó por causa del golpe militar.

Los tópicos abarcadosen sus trabajos deinvestigación son casi tan variados como sus intereses: sociedades complejas, arqueología de las creencias, interacciones intersocietales, espacialidad en arqueología, antropología política en prehistoria, discursos visuales en prehistoria, chamanismo (Sinclaire 2018). Con intereses específicos en los desarrollos culturales Tiwanaku, periodo Intermedio Tardío e Inka, arte rupestre, arqueología de la vialidad prehispánica y de las espacialidades internodales. Aunque para Berenguer la arqueología debe también abarcar el pasado reciente, tal como lo ejemplifica su compromiso y trabajo con la búsqueda y exhumación de detenidos-desaparecidos y ejecutados políticos de la dictadura en Chile. Notable ha sido su dedicación al investigar Taira (Berenguer 1995; Berenguer y Martínez 1986a, 1986b) y otros estilos de arte rupestre del Alto Loa (Berenguer 1999; Berenguer et al. 1985) y Atacama (Berenguer 2004b). En Taira, junto con Martínez, lleva adelante una "aproximación contextual", vinculando, como propuesta, al Río Loa, "al arte rupestre de Taira y al mito de Yakana como un conjunto significante: el de las creencias relativas a la creación y conservación del ganado" (Berenguer y Martínez 1986a:97). Este significativo trabajo marca un acercamiento inédito hacia el arte rupestre en nuestro país. Caminante incansable tras las rutas y caminos del Inka en el Loa y en Tarapacá, definió el trazado de más de $100 \mathrm{~km}$ desde el Loa Medio en Lasana al Alto Loa, en las nacientes del Miño. Valga destacar que nuestro homenajeado estudia el Qhapaq Ñan desde una perspectiva holística (Berenguer 2007) (Sinclaire 2018), integrando diversos componentes investigativos. En 2001 tuve la oportunidad de participar en su proyecto FONDECYT: "Arqueología del sistema vial de los Inkas en el Alto Loa, Región de Antofagasta", que fue para el suscrito un auténtico "aprendizaje vial", que marcó el inicio de mi dedicación hacia el estudio del Qhapaq Ñan. Eso fue posible por el espacio de enseñanza que Berenguer propiciaba, no solo para mí, sino para todos quienes formamos parte de su equipo.

Autor de más de 70 artículos, 12 libros como autor, 10 libros colectivos, 37 capítulos de libros y siete prólogos y presentaciones (Sinclaire 2018); sus trabajos se han publicado en Chile, Argentina, Perú, Bolivia, Ecuador, Estados Unidos, Francia, Italia, Corea del Sur y Australia.

Desde 1986 hasta el presente, ha cumplido funciones como editor del Boletín del Museo Chileno de Arte Precolombino, convirtiéndolo en una de las revistas más importantes en nuestras temáticas en Sudamérica y probablemente la única consagrada al arte precolombino al sur del Río Grande. Del mismo modo, desde 1981 a la fecha, es Curador Jefe del referido museo, con más de 30 exposiciones a su cargo (Sinclaire 2018). De hecho, ha sido uno de los pilares en convertir esta institución museológica en uno de los espacios culturales más visitados en Chile. En este lugar, la oficina de "Pepe", siempre abierta y donde sus ideas cubren todos los rincones, es hasta ahora un foco de conversación arqueológica y humana, de charlas siempre orientadoras y afectuosas. Ese fecundo diálogo ha nutrido nuestras investigaciones $\mathrm{y}$, por igual, ha hecho crecer nuestras vidas.

Finalmente, señalar que sus importantes contribuciones arqueológicas en el plano teórico y en las interpretaciones sobre el pasado en Chile y los Andes, han enriquecido, indudablemente, nuestra disciplina, traspasando fronteras. Por tales razones, profesionales y humanas, tengo el honor, a nombre del Comité Organizador del Taller Internacional Qhapaq Ñan II, de reconocer el valor de la obra, que proseguirá entregando relevantes frutos, del arqueólogo Dr. José Berenguer Rodríguez, para quien pido de todas y todos los presentes, un gran y merecido aplauso. 


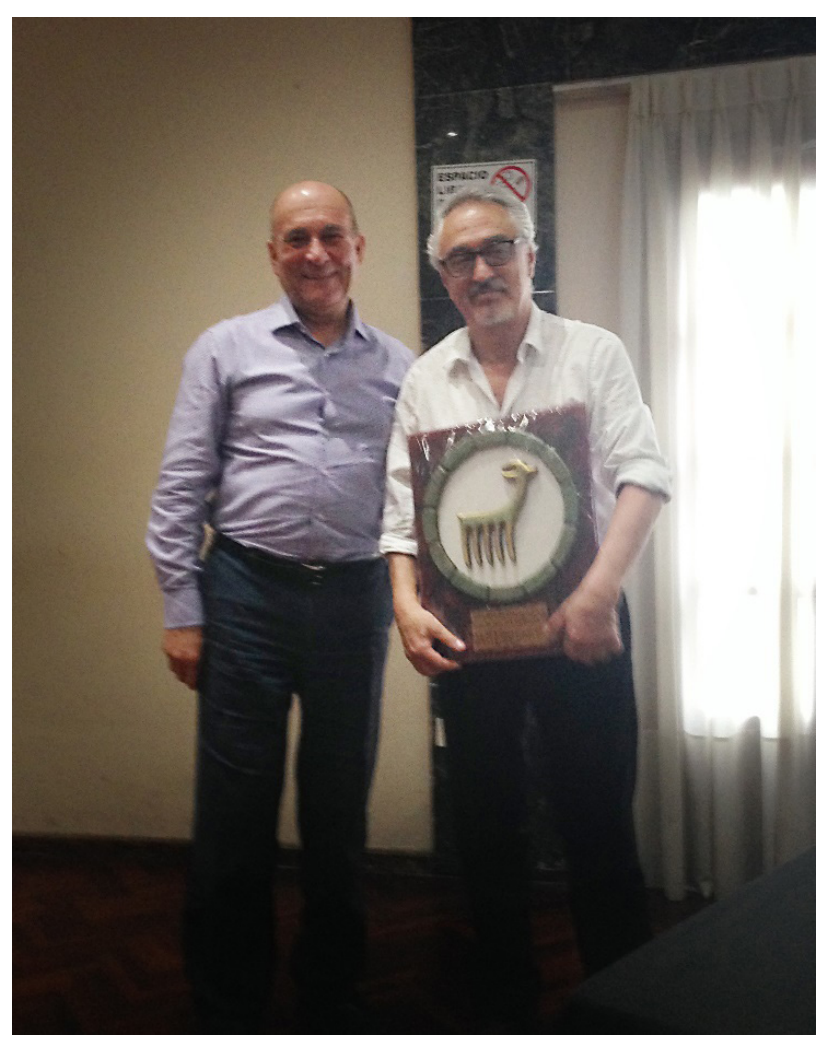

Dr. José Berenguer recibe distinción por parte del Dr. J. Roberto Bárcena, a nombre del Comité Organizador del Taller Internacional Qhapaq Nan II (26-10-2017, Salta, Argentina).

\section{Referencias Citadas}

Aldunate, C., J. Berenguer, V. Castro, L. Cornejo, J.L. Martínez y C. Sinclaire 1986. Sobre la cronología del Loa Superior. Chungara Revista de Antropología Chilena 16-17:333-346.

Berenguer, J. 1995. El arte rupestre de Taira en el contexto de los problemas de la arqueología atacameña. Chungara Revista de Antropología Chilena 27 (1):7-43.

Berenguer, J. 1999. El evanescente lenguaje del arte rupestre en los Andes atacameños. En Arte Rupestre en los Andes de Capricornio, editado por J. Berenguer y F. Gallardo, pp. 9-54. Museo Chileno de Arte Precolombino, Santiago.

Berenguer, J. 2000. Tiwanaku. Señores del Lago Sagrado. Museo Chileno de Arte Precolombino, Santiago.

Berenguer, J. 2004a. Caravanas, Interacción y Cambio en el Desierto de Atacama. Sirawi Ediciones, Santiago.

Berenguer, J. 2004b. Cinco milenios de arte rupestre en los Andes atacameños: Imágenes para lo humano, imágenes para lo divino. Boletín del Museo Chileno de Arte Precolombino 9:75-108.

Berenguer, J. 2007. El camino inka del Alto Loa y la creación del espacio provincial en Atacama. En Producción y Circulación Prehispánicas de Bienes en el Sur Andino, compilado por A.E.
Nielsen, M.C. Rivolta, V. Seldes, M.M. Vásquez y P.H. Mercolli, pp. 413-443. Editorial Brujas, Córdoba.

Berenguer, J. y J.L. Martínez 1986a. El río Loa, el arte rupestre de Taira y el mito de Yakana. Boletín del Museo Chileno de Arte Precolombino 1:79-99.

Berenguer, J. y J.L. Martínez 1986b. Camelids in the Andes: Rock art, environment and myths. En Animals into Art, editado por H. Morphy, pp. 390-416. Unwin Hyman, London.

Berenguer, J., V. Castro, C. Aldunate, C. Sinclaire y L. Cornejo 1985. Secuencia del arte rupestre en el Alto Loa: Una hipótesis de trabajo. En Estudios en Arte Rupestre, editado por C. Aldunate, J. Berenguer y V. Castro, pp. 87-108. Museo Chileno de Arte Precolombino, Santiago.

Nielsen, A. 2006. Caravanas, Interacción y Cambio en el Desierto de Atacama de José Berenguer Chungara Revista de Antropología Chilena 38 (1):158-161.

Sinclaire, C. 2018. José Berenguer. En Encyclopedia of Global Archaeology, editado por C. Smith. Springer, Cham. https://link.springer. com/referenceworkentry/10.1007\%2F978-3-319-51726-1_3346-1 (17 junio 2019).

\section{Nota}

${ }^{1}$ El manuscrito de Sinclaire fue conocido por el autor del homenaje en 2017 , pero en esta versión fue consignado con la fecha de su respectiva publicación. 
